\title{
Med vuxenpedagogik i tiden
}

\section{Om att bli människa och medborgare}

\author{
PETRI SALO
}

$\mathrm{M}$ änniskoblivandet handlar om att förstå sig själv och sina medmänniskor, och om att kunna påverka de samhälleliga villkoren för människoblivandet. Vuxenpedagogens projekt har genom tiderna varit både pedagogiskt och politiskt. Projektet har handlat om att främja de villkor och processer genom vilka man blir medmänniska och medborgare. Människoblivandets två aspekter svarar mot varsin metodologisk ansats och återspeglas i ett givet kunskapsintresse. Inom den tolkande ansatsen med ett praktiskt kunskapsintresse är syftet att förstå och upprätthålla människan som kulturvarelse. Detta sker genom språk och genom kommunikation. Lärandet gestaltas som en meningsskapande aktivitet. Syftet med den kritiska ansatsen med ett kritiskt-emancipatoriskt kunskapsintresse är att påverka och förändra samhället. Påverkansprocesserna bygger på en kritisk reflektion över de existerande maktförhållandena, deras legitimitet och uttrycksformer. Lärandet gestaltas som en kritisk reflektion med förnyelse genom emancipation och frigörelse som syfte. Båda människoblivandets aspekter och ansatser är samtidigt individuella och kollektiva, i dem förenas lärande och aktion - pedagogik och politik. Vuxenpedagogiken är både en human- och en samhällsvetenskap. Som samhällsvetenskap borde den vara kapabel till kritisk reflektion kring villkoren för människoblivandet. ${ }^{1}$

Det nordiska välfärdssamhällets idé planterades för drygt hundra år sedan i sociala rörelser, $\mathrm{i}$ folkbildning och i studiecirklar. Det är på dessa pedagogisk-politiska arenor vår gestaltning av vad det innebär att vara människa och medborgare tar form. Folk, social och cirkel står för den politiska dimensionen - rörelse, bildning och studier för den pedagogiska dimensionen. Inom den första generationens sociala rörelser - väckelse-, nykterhets-, arbetar- och kvinnorörelsen omsatte man den franska revolutionens slagord frihet, jämlikhet och gemenskap i praktiken. ${ }^{2}$ I Finland når des-

sa pedagogisk-politiska projekt sin kulmen på 1960- och 1970-talen, genom grundskolan och det som nästan hånfullt idag benämns massuniversitet. Men båda koncepten har visat sig vara mycket framgångsrika, i smått och stort - för mig personligen och för nationen Finland.

Jag uppfattar sociala rörelser, folkbildning och studiecirklar som Både-Och fenomen. De svarar mot bildningsbegreppets två varandra kompletterande dimensioner, processen och målet. Utmaningen handlar om att bli någon och något; växa som människa och aktivera sig som medborgare. Medborgarskap är åtminstone än så länge ett tillstånd, eller ett ideal man kan uppnå medan projektet för att fördjupa förståelsen för människan som kulturvarelse pågår av nödtvång från vaggan till graven. ${ }^{3}$ Teknik och ekonomi är underställda människoblivandet och bildningen, särskilt i ett kunskaps- och informationssamhälle. De är, såsom vuxenpedagogisk forskning och vuxenutbildning med syfte att effektivera eller kvalitetssäkra arbete eller de organisatorisk-samhälleliga villkoren för arbete, medel och verktyg för människo-blivandet, inte dess mål eller syfte.

Allt har förändrats, ingenting är sig likt. Gamla paradigm och gestaltningar måste ersättas med nya, modernare, uppdaterade. Detta gäller även lärandeparadigm. Lärandet bör relateras till, förstås och studeras i förhållande till den kontext den uppkommer i. Vi behöver en mer dynamisk, öppen och mångfacetterad gestaltning av lärandet. Denna gestaltning bör förutom den kognitiva, kunskapsmässiga aspekten omfatta det emotionella, det moraliska och det fysiska. Och kanske är det så att lärande i dess egentliga mening är samtidigt en förutsättning, ett medel för och ett utfall av handling och aktion. ${ }^{4}$

Dessa nästan nyfrälsta insikter är inte särskilt ovanliga i vår tid. De framförs på arenor av diverse slag av (vuxen)pedagoger med avec. De nya utmaningarna skall hanteras med en sociokognitiv, - 
konstruktivistisk eller - kulturell gestaltning av lärandet. Kortfattat handlar dessa lärandegestaltningar om hur man i växelverkan med andra människor i ett givet kulturellt, socialt eller samhälleligt sammanhang, utgående från varierande erfarenheter genom handlingar och aktioner i vardagen på ett reflektivt sätt konstruerar och skapar mening. Som vuxenpedagog undrar man ständigt vad som är det nya i det nya. Mitt svar på samtliga av de så kallade nya utmaningarna är studiecirkel möjlighet att inom ramen för en gemenskap, frivilligt och på jämlika grunder utveckla och förverkliga både sig själv, sina medmänniskor och sina medborgare. Den svenska folkbildningsforskaren Petros Gougoulakis ${ }^{5}$ konstaterar att:

Studiecirkelverksamhetens fria och frivilliga särdrag verkar vara nära förknippade med omhuldade vuxenpedagogiska ideal.

Därefter räknar han upp dessa ideal: självbildning, kollaborativt, öppet och flexibelt lärande, erfarenhetsbaserat och individanpassat lärande, kontextualitet, mening, sammanhang och inflytande. Att lära sig om sig själv, sin samtid och sitt samhälle tillsammans med andra. Det handlar om livskvalitet med inslag av humankapital, socialt kapital och identitetskapital. ${ }^{6}$ Kapitalbegreppet används numera mycket kreativt även om referenserna är några årtionden gamla. ${ }^{7}$

För en vuxenpedagog med intresse för folkbildningsforskning framstår dagens nyandliga lärandehysteri som ahistorisk och apolitisk. I de nordiska folkrörelserna var man inte särskilt intresserad av eller fokuserad på lärande i sig. Lärandet uppstod snarare som en biprodukt av kollektiva aktioner med syfte att påverka och förändra det sociala livets villkor. Studiecirkeln var en arena för pedagogisk-politisk verksamhet.

Det sociala och politiska engagemanget, i vilket individuella och kollektiva strävanden sammanföll på ett fruktbart sätt, var ett kännetecken för folkbildningen i dess begynnelse. Men detta engagemang kom att institutionaliseras och inkorporeras i välfärdsstaten. Folkbildning som politisk aktivism och motkultur fick ge vika för vuxenpedagogiken som ett pragmatiskt åtgärdsinstrument. ${ }^{8}$

\section{Vuxenpedagogik och aktionsforskning}

I februari 2008 hade jag förmånen att närvara vid en föreläsning som hölls av professorn i pedagogisk filosofi från University of Sheffield, Wilfred Carr. Temat för föreläsningen var aktionsforskning. Han inledde föreläsningen på följande sätt:

There are two problems with action research, the first is action and the second is research.

Jag återkommer till hans gestaltning av aktionsforskning senare. Men jag applicerar hans grundresonemang på vuxenpedagogik; vuxenpedagogiken som vetenskaps-område brottas med två problem - vuxenhet och pedagogik.

Vuxenheten är en kulturell, social och politisk konstruktion vars uttrycksformer och funktion varierar över tid och kontext. Den institutionaliserade definitionen av vuxenhet inom ramen vuxenutbildning är inte längre ändamålsenlig, om den någonsin varit det. I ett individualiserat sen- eller postmodernt samhälle $\mathrm{i}$ vilket vi tyranniseras av en oändlig valfrihet är vuxenheten i allra högsta grad flytande, ett oavslutat projekt bland andra oavslutade projekt. $^{9}$

Vem är idag vuxen sin uppgift - kapabel att på ett moget och självständigt sätt ta ansvar för den arbetsuppgift som man formellt blivit tilldelad? Inte jag som nyutnämnd professor i arbetsorganisationen universitet. De prestationsteknologier som idag omfattar utbildning och den offentliga sektorn, och som går ut på att organisera, styra, leda, reglera och kontrollera kunskapsarbete, infantiliserar den vuxne professorn och alienerar honom, inte bara från sitt kunskapsarbete utan även från den akademiska verksamheten som livsstil. För läraren i skolan är situationen densamma. Med Stephen Balls ord handlar det om en "performativitet som terroriserar lärarens själ." "10

Den tve- eller mångtydiga vuxenheten i vår tid kan jämföras med ett postnationellt medborgarskap. Medborgarskap inom ramen för nationalstaten framställs som en status, ett tillstånd som man i bästa fall kan uppnå. Med medborgarskap som status följer vissa skyldigheter och rättigheter. Dessa omfattar politik, rättväsende och det sociala livet. Det aktiva, postnationella medborgarskapet kan däremot uppfattas som funktionellt, en roll som ständigt måste upprätthållas och utvecklas. Den är mer dynamisk och flytande, en arena eller scen för varierande identitetskonstruktioner. I bästa fall, sett ur ett folkbildningsperspektiv, kommer det funktionella medborgar-skapet till uttryck i ett varaktigt engagemang och delaktighet i lokala eller globala gemenskaper. ${ }^{11}$ 
Problemet med pedagogiken handlar (a) om att den fortfarande förknippas så starkt med institutionaliserad utbildning och undervisning, med fokus på lärarprofessionen, undervisning och lärande, (b) om en relativt meningslös akademisk armbrytning om de två områdenas förhållande till varandra. Sin vuxenhet till trots verkar vuxenpedagoger under årtionden ha lidit av en identitetskris eller en mindervärdeskomplex. Som resultat har man försökt distansera sig från pedagogiken genom att ersätta vuxenpedagogik med andragogik, eller genom att betona självstyrning som ett särdrag för den vuxnes lärande. Man har även försökt utveckla en egen teorigrund och begreppsapparat som inte skulle vara kontaminerad av till exempel psykologin eller sociologin ${ }^{12}$. Dessa försök har varit mer eller mindre misslyckade, därför att i en strävan efter en självständig och - tillräcklig status som vetenskap har man missat den springande punkten - att vuxenpedagogiken är en humanvetenskap och en samhälls-vetenskap. Vuxenpedagogiken är Varken-Eller, den är Både-Och. På senare tid har vuxenpedagoger förmått greppa och förstå detta, börjat uppfatta sig själv som representanter för en diskussions- och brovetenskap. ${ }^{13}$

Kopplingen mellan aktionsforskning och vuxenpedagogik är inte enbart retorisk. Vuxenpedagogik är aktionsforskning precis som aktionsforskning är vuxenpedagogik. Intresset riktas mot lärande, utveckling och forskning i aktion. Det må handla om

- den vuxnes målinriktade studier inom vuxenutbildningen

- inlärning i, med och för arbete och ett arbetsliv i omvandling,

- professions-, ledarskaps- eller personalutveckling i kunskapsorganisationer

- artikulering av och möjligheterna att dra nytta av tyst erfarenhetsbaserat kunnande

- den vuxna människans konstruktion och för verkligande av sig själv, sin identitet i en livs lång människoblivandeprocess, $\mathrm{i}$ ett dyna miskt och mångfacetterat vardags-livsperspektiv.

Dessa är fenomen som man inom den vuxenpedagogiska forskningen på senare tid riktat sitt intresse mot. ${ }^{14}$ Intresset för vuxnas lärande och utveckling i aktion i varierande kontexter är idag mycket utbrett även bland ekonomer, personalutvecklare, marknadsförare, statsvetare, socialpolitiker, arbetslivs- och ledarskapsforskare, och or- ganisationsteoretiker. ${ }^{15}$

I ett historiskt medvetet folkbildningsperspektiv kunde vuxenpedagogerna rehabilitera och återmobilisera studiecirkeln som arbets- och aktionsform. Detta för att till fullo förverkliga vetenskapsområdets karaktär som diskussions- och brovetenskap. Vi bör inte heller glömma att studiecirkeln i dess nordiska tappning vidareutvecklades framgångsrikt från och med 1960-talet i form av deltagande aktionsforskning och forskningscirklar i arbetslivet, ofta förverkligade i fruktbar samverkan mellan forskare och praktiker. I Finland representeras denna tradition idag främst av den utvecklande arbetslivsforskningen. ${ }^{16}$

Precis som folkbildningen är den nordiska modellen för deltagande aktionsforskning i arbetslivet $\mathrm{i}$ allra högsta grad politisk. Syftet har varit och är att främja demokrati, öka olika aktörers delaktighet i beslutsfattande, skapa jämlika möjligheter till medverkan och delaktighet i fenomen och utmaningar inbäddade i ens livsvärld. ${ }^{17}$ Detsamma gällde för socialt arbete, lokalt utvecklingsarbete och lokala demokratiprojekt t.ex. i Sverige på 1960och 1970-talen. I Finland har vuxenpedagogiken haft en stark institutionell förankring. Kanske är detta orsaken till att lokalt förankrat forskande utvecklings- och förändringsarbete, i vilket människor engageras i sin närmiljö för att påverka sin situation och levnadsmiljö tillsammans med sina medmänniskor, inte fått särskilt stort fotfäste. Utanför Norden har vi däremot en rik och mångfacetterad tradition som på engelska går under benämningen community adult education. ${ }^{18}$

\section{Den vuxenpedagogiska forskningens döda vinklar}

Det finns några uppenbara döda vinklar inom vuxenpedagogisk forskning. Den första gäller för pedagogik och utbildning överlag. Jag hävdar att vi inte längre uppfattar och behandlar demokrati som ett politiskt begrepp, även om det i allra högsta grad är det. En skola för demokrati är inte vilken skola som helst. Detsamma gäller för aktivt medborgarskap, ett aktuellt begrepp både i skola och vuxenutbildning. Men det är som om medborgarskapet i aktivt medborgarskap skulle ha dekontextualiserats, som om det bara skulle handla om medborgaren på arbetsmarknaden eller i staten "Jag".

För det andra har vi de överaktiva globala medborgarna, eller motborgarna, aktivisterna i globala rättvise- eller globalisationskritiska rörelser, den 
tredje generationens sociala rörelser ${ }^{19}$. Trots att vuxenpedagogik som vetenskapsområde, folkbildning och vuxenutbildning som institutioner, står på den grund man lade inom den första och andra generationens sociala rörelser, förmår man idag inte omfatta detta aktuella fenomen. Detsamma gäller för de intressebaserade globala och virtualiserade nya studiecirklarna dvs bloggar, diskussionsforum, Facebook, MySpace, Linkedn, Second life m.fl. I dessa samlas vuxna idag för att skapa och upprätthålla kontakter, för att dela med sig av sina intressen och erfarenheter, för att diskutera och polemisera, för att konstruera och förverkliga sig själva.

Den tredje döda vinkeln i vuxenpedagogisk forskning handlar om den vuxna lärarens och rektorns arbete i arbetsorganisationen skolan. Trots omfattande arbetslivsforskning har detta område långt blivit förbisett av vuxenpedagoger. Alternativt uppfattas det som ett eget forskningsområde, men inte som ett vuxenpedagogiskt sådant. Genom att betrakta vuxenpedagogik som aktionsforskning kan vi komma åt den vuxna lärarens arbete $\mathrm{i}$ skolan, och på så sätt skapa underlag för en hållbar utveckling av skolan.

Aktionsforskningens historia kan indelas i två skeden. Den typ av aktionsforskning som Kurt Lewin utvecklade på 1920-talet gick ut på att applicera samhällsvetenskapliga teorier i praktiken samt pröva dessa teoriers praktiska genomslagskraft, deras effekter. Förhållningssättet till aktionsforskning var rätt instrumentellt. I det andra skedet i början 1970-talet återuppstod aktionsforskning inom skola och utbildning, som en reaktion på den pedagogiska forskningens oförmåga att omfatta lärarens och skolans vardagliga utmaningar. Syftet var att förse läraren med färdigheter och beredskap att forska i och utveckla sitt arbete i skolan. Aktionsforskningen skulle omfatta mera än bara lärarens arbete. Den berörde även skolans mål, funktion och uppgift i samhället. Den forskande läraren skulle pröva och utveckla de pedagogiska teorierna inbäddade i sina handlingar. Hon skulle förhålla sig till dessa teorier som experimentella hypoteser som hon systematiskt relaterade till och på så sätt utvärderade i en given organisatorisk och samhällelig kontext. ${ }^{20}$

Wilfred Carr och Stephen Kemmis definierar aktionsforskning i sin bok Becoming critical. Education, knowledge and action research ${ }^{21}$ enligt följande:

Det är helt enkelt en form av självreflektiv stu- die som aktörerna i ett givet socialt sammanhang genomför med syfte att utveckla rationaliteten och rättviseaspekterna i sin praktik, sin egen förståelse av praktiken samt de vidare sammanhang i vilka denna praktik utformas.

Cirkeln är sluten. I min läsning är detta en definition på en praktisk studiecirkel. Aktionsforskning är vuxenpedagogik, och vuxenpedagogik är aktionsforskning

\section{Rehabilitering av praxis}

Det har blivit dags att återvända till Wilfred Carr och påståendet om aktion och forskning som aktionsforskningens två problem. I båda fallen handlar problemet om ett naturvetenskapligt ideal om objektivitet. Objektiviteten förankras i ett utanförskap och distansering genom teoretisk kunskap $a$ priori, före eller oberoende av erfarenhet. Den appliceras på human- oh samhällsvetenskaplig forskning och tillåts utforma dess metodologiska verktygslåda. Antagandet är att vi människor kan bli oberoende av och agera genom att ställa oss utanför oss själva och våra medmänniskor. Detsamma gäller för den erfarenhet vi samlat på oss. Problemet är att aktionsforskning definieras och utvecklas enbart som en metodologi med referens till de naturvetenskapliga idealen, som ett kliniskt och steriliserbart verktyg. På motsvarande sätt utvecklas politisk, sociologisk och pedagogisk teori med ambitionen att kunna studera politiska, sociologiska och pedagogiska praktiker på distans, icke-normativt och fritt från värderingar, utan historisk, kulturell, social eller politisk barlast.

I artikeln "Partisanship in Educational Research" hänvisar Wilfred Carr ${ }^{22}$ till vetenskapsteori utvecklad för samhällsvetenskaper från 1960- till 1980-talet och drar följande slutsats:

Problemet med partisanskap (dvs. att man bekänner färg och tillhörighet) kvarstår bara för dem som håller sig fast vid en filosofiskt oupplyst och intellektuellt naiv syn på pedagogisk forskning som en ren teknisk och metodisk aktivitet, som både kan och bör vara obesmittad av politik, värderingar och ideologi.

Jag har svårt att uppfatta detta som särskilt provokativ. Men däremot uppfattar jag Wilfred Carrs och Stephen Kemmis ${ }^{23}$ ambition att rehabilitera aktionsforskning genom att ty sig till Aristoteles som en konstruktiv provokation. Rehabiliteringen sker genom att återlansera praxis. Praxis är vid 
sidan om theoria och poiesis en av de tre formerna för mänskligt handlande, aktion. Praxis är att göra rätt, agera klokt och anständigt. Praxis är den moraliskt-etiskt välgrundade och historiskt medvetna handlingen, den hållbara handlingen. Den bygger på fronesis, praktisk klokhet. I praxis är handlingen i sig målet. Praxis handlar om att vilja sina medmänniskor och sina medborgare, och genom dem sig själv väl. Samtidigt som praxis är historiskt medveten är den i allra högsta grad situationsbunden. Önskar man någon väl är det klokt, vist och anständigt att börja här och nu. Praxis är socialt handlande, den bygger på social interaktion och koordinering, förutsätter samtal och samverkan. I förmodern, modern och senmodern tid är det två domäner som praxis hör till - pedagogik och politik. Wilfred Carr skriver:

Aktionsforskning blir endast begriplig som en metod för att studera och förhålla sig till verkligheten på ett sätt som aspirerar på att skapa och upprätthålla samfund som bygger på fortlöpande samtal [] .. och inom vilka man känns vid att praktisk kunskap och förståelse kan endast utvecklas och främjas av praktiker engagerade $i$ sådana dialoger och diskussioner genom vilka de blir varse sina implicita $i$ tradition inbäddade antaganden om sina egna handlingar, och är beredda att omvärdera och omvandla sin kollektiva förståelse av praxis.

Något förenklat menar han att hållbar mänsklig utveckling, må det sedan gälla kulturen, samhället eller organisationen, måste bygga på att man tillsammans med andra diskuterar vad och varför man har gjort det man har gjort, vad man tror på, vad man vill och vad man är beredd att göra - det vankas studiecirkel.

Som vuxenpedagog vill jag beskriva praxis som den vuxna, själsligt och andligt mogna handlingen. Som finländsk vuxenpedagog hänvisar jag, till den förste och störste, Urpo Harva. Han motiverar livslång vuxenfostran - aikuiskasvatus för över fem årtionden sedan genom att ta fasta på den livslånga själsligt-andliga utvecklingen. ${ }^{24}$

För det första handlar den om den mognad av personligheten som hör till uppgiften att växa till och som förälder. Ytterligare kännetecknas vuxenheten av en etisk-existentiell mognad. Den bygger på en vilja och förmåga att höja sig ovanför sina förutfattade meningar och personliga begränsningar, för att förmå beakta alla de kvaliteter och dimensioner som livet består av.
Vi är alla barn av vår egen tid. Vi blir till människor, möjligtvis vuxna sådana, och växer som människor tillsammans med andra människor. Den livslånga mognads- och tillväxtprocessen genom vilken vi blir till - ger näring åt den kultur och åt det samhälle vi ingår i. Vi påverkas av och påverkar fortlöpande det samhälle vi dagligen agerar i. Detta sker i ett flertal varandra kompletterande, emellanåt utmanande roller och uppgifter. Samtidigt som vi, för att kunna bli mera människor, göra oss verkliga för oss själva och för andra, kommer vi inte ifrån det faktum att vi är inbäddade, försjunkna i vårt samtida samhälle. Vi andas och lever av vår samtidsanda. Det är zeitgeisten vi får syre av och fortlöpande förser med koldioxid.

\section{Litteraturlista}

Allardt, E. (1975). Att ha, att älska, att vara: om välfärd I Norden. Lund: Argos

Ball, S. (2003). The teacher's soul and the terrors of performativity. Journal of Education Policy, 18(2), 215-228.

Boyd, R.D. \& Apps, J.W. Redefining the discipline of adult education. San Francisco : Jossey-Bass.

Carr, W. (2006). Philosophy, methodology and action research. Journal of Philosophy of Education, 40 (4), 421-435.

Carr, W. (2000). Partisanship in educational research. Oxford Review of Education, 26 (3/4), 437-449.

Carr, W. \& Kemmis, S. (1986). Becoming Critical. Education, Knowledge and Action Reearch. London and Philadelphia: Falmer Press.

Conczi. A. (2004). The new professional and vocational education. I G. Foley (red.) Dimensions of adult learning. Adult education and training in a global era. Maidenhead: Open University Press, 19-24.

Finger, M. 1990. Does adult education need a philosophy? Reflections about the function of adult learning in today's society. Studie in Continuing Education, 12 (2), 99-106.

Gougoulakis, P. 2002. Har studiecirkeln någon framtid? I H. A. Bengtsson (red.) Folkbildning $i$ vår tid. En antologi om makt och demokrati. Stockholm: Atlas, 152-183. 
Gustavsson, B. (1991). Bildningens väg. Tre bildningsideal $i$ svensk arbetarrörelse 18801930. Helsingborg: Wahlström \& Widstrand.

Harva. U. (1955). Aikuiskasvatus. Johdanto aikuiskasvatuksen teoriaan ja työmuotoihin Suomessa. Helsinki: Otava.

Horsdal, M. (2001). Kulturmøde og medborgerskab. I J. Gleerup (red.) Voksenuddannelse under forandring. København: Gad. Kemmis, S. Smith, T.J. (red.) Enabling praxis. Challenges for education. Rotterdam: Sense Publishers.

Korsgaard, O. (2001). The struggle regarding citizenship. From social citizenship to active citizenship. From adult education to lifelong learning. I O. Korsgaard, S. Walters \& R. Andersen (red.) Learning for democratic citizenship. Copenhagen: Association for world education and the Danish University of Education.

Koski, L. \& Moore, E. (2001). Näkökulmia aikuisuuteen ja aikuiskasvatukseen. Aikuiskasvatus, 21 (1), 4-13.

Larsson, S. (2001). Seven aspects of democracy related to study circles. International Journal of Lifelong Education, 3 (20), 199-217.

Lindholm, A. (2005). Maailman parantajat. Globalisaatiokrittiinen liike Suomessa. Helsinki: Gaudeamus.

Nordvall, H. I skärningspunkten mellan det globala och det lokala. Tolkningsprocesser och koalitionsbygge $i$ organiseringen av lokala sociala forum. Linköping: Linköpings universitet.

Rinne, R., Heikkinen, A. \& Salo, P. (2007). Liberty, Fraternity, Equality - A French introduction to Nordic adult education. I R. Rinne, A. Heikkinen \& P. Salo (Eds.) Adult educationLiberty, Fraternity, Equality? Nordic views on lifelong learning.Turku: Finnish Educational Research Association, 9-15.

Rönnerman, K. Salo, P. \& Moxnes Furu, E. 2008. Action Research in the Nordic Countries: A Way to See Possibilities. I K. Rönnerman, E. Furu \& P. Salo (Eds.) Nurturing praxis - Action Research in Partnerships Between School and University in a Nordic light. Rotterdam: Sense Publishers, 21-37.

Salling Olesen, H. (2006). Beyond abstractions! Adult education research from idealism to cri- tical social science. International journal of Lifelong Education, 25 (3), 241-256.

Salo, P. (1998). Yhteisö, kasvatus ja arjessa oppiminen. I P. Sallila \& T. Vaherva (Red.). Arkipäivän oppiminen. Aikuiskasvatuksen 39. vuosikirja. Helsinki: Kansanvalistusseura, 178-199.

Salo, P. (2006). Mitä on suomalainen aikuiskasvatus? Aikuiskasvatus, 26 (4), 289-295.

Schuller, T. Preston, J. Hammond, C., BrassetGrundy, A \& Bynner, J. (2004). The benefits of learning. The impact of education on health, family life and social capital. London: RoutledgeFalmer.

Schwartz, B. (2001). Self-Determination. The tyranny of Choice. American psychologist, 55 (1), 79-88.

Simola, H. (2008). Kasvatustiede yhteiskuntatieteenä - pohdintoja suomalaisen kasvatustieteen edellytyksistä yhteiskuntakritiikkiin jaanalyysiin. I P. Siljander \& A. Kivelä (red.). Kasvatustieteen tila ja käytännöt. Turku: Suomen kasvatustiteellinen seura, 393-417.

Suoranta, J., Kauppila, J. \& Salo, P. (2008). Aikuiskasvatus siltatieteenä. I J. Suoranta, J. Kauppila, H. Rekola, P. Salo, P. \& M. Vanhalakka-Ruoho (Red.) 2008. Aikuiskasvatuksen risteysasemalla. Johdatus aikuiskasvatukseen. Joensuu: Joensuun yliopiston täydennyskoulutuskeskus, 9-20.

\section{Referenser}

1. Salling Olesen, H. (2006). Beyond abstractions! Adult education research from idealism to critical social science. International journal of Lifelong Education, 25 (3), 241-256.

Simola, H. (2008). Kasvatustiede yhteiskuntatieteenä - pohdintoja suomalaisen kasvatustieteen edellytyksistä yhteiskuntakritiikkiin ja-analyysiin. I P. Siljander \& A. Kivelä (red.). Kasvatustieteen tila ja käytännöt. Turku: Suomen kasvatustiteellinen seura, 393-417.

2. Rinne, R., Heikkinen, A. \& Salo, P. (2007). Liberty, Fraternity, Equality - A French introduction to Nordic adult education. I R. Rinne, A. Heikkinen \& P. Salo (Eds.) Adult education - Liberty, Fraternity, Equality? Nordic views on lifelong learning. Turku: Finnish Educational Research Association, 9-15. 
3. Gustavsson, B. (1991). Bildningens väg. Tre bildningsideal $i$ svensk arbetarrörelse 18801930. Helsingborg: Wahlström \& Widstrand.

4. Conczi. A. (2004). The new professional and vocational education. I G. Foley (red.) Dimensions of adult learning. Adult education and training in a global era. Maidenhead: Open University Press, 19-24.

5. Gougoulakis, P. (2002). Har studiecirkeln någon framtid? I H. A. Bengtsson (red.) Folkbildning $i$ vår tid. En antologi om makt och demokrati. Stockholm: Atlas, 152-183.

6. Schuller, T. Preston, J. Hammond, C., BrassetGrundy, A\& Bynner, J. (2004). The benefits of learning. The impact of education on health, family life and social capital. London: RoutledgeFalmer.

7. Allardt, E. (1975). Att ha, att älska, att vara: om välfärd I Norden. Lund: Argos

7. Finger, M. (1990). Does adult education need a philosophy? Reflections about the function of adult learning in today's society. Studie in Continuing Education, 12 (2), 99-106.

8. Larsson, S. 2001. Seven aspects of democracy related to study circles. International Journal of Lifelong Education, 3 (20), 199-217.

9. Koski, L. \& Moore, E. 2001. Näkökulmia aikuisuuteen ja aikuiskasvatukseen. Aikuiskasvatus, 21 (1), 4-13.

Schwartz, B. (2001). Self-Determination. The tyranny of Choice. American psychologist, 55 (1), 79-88.

10. Ball, S. (2003). The teacher's soul and the terrors of performativity. Journal of Education Policy, 18 (2), 215-228.

11. Horsdal, M. (2001b). Kulturmøde og medborgerskab. I J. Gleerup (red.) Voksenuddannelse under forandring. København: Gad.

Korsgaard, O. (2001). The struggle regarding citizenship. From social citizenship to active citizenship. From adult education to lifelong learning. I O. Korsgaard, S. Walters \& R. Andersen (red.) Learning for democratic citizenship. Copenhagen: Association for world education and the Danish University of Education.

12. Boyd, R.D. \& Apps, J.W. Redefining the discipline of adult education. San Francisco: Jossey-Bass.

13. Suoranta, J., Kauppila, J. \& Salo, P. (2008). Aikuiskasvatus siltatieteenä. I J. Suoranta, J. Kaup- pila, H. Rekola, P. Salo, P. \& M. Vanhalakka-Ruoho (Red.) 2008. Aikuiskasvatuksen risteysasemalla. Johdatus aikuiskasvatukseen. Joensuu: Joensuun yliopiston täydennyskoulutuskeskus, 9-20.

14. Salo, P. (2006). Mitä on suomalainen aikuiskasvatus? Aikuiskasvatus, 26 (4), 289-295.

15. Salling Olesen, H. (2006). Beyond abstractions! Adult education research from idealism to critical social science. International journal of Lifelong Education, 25 (3), 241-256.

16. Rönnerman, K. Salo, P. \& Moxnes Furu, E. 2008. Action Research in the Nordic Countries: A Way to See Possibilities. I K. Rönnerman, E. Furu \& P. Salo (Eds.) Nurturing praxis - Action research in partnerships between school and university in a Nordic light. Rotterdam: Sense Publishers, 2137.

17. Salling Olesen, H. (2006). Beyond abstractions! Adult education research from idealism to critical social science. International journal of Lifelong Education, 25 (3), 241-256.

18. Salo, P. (1998). Yhteisö, kasvatus ja arjessa oppiminen. I P. Sallila \& T. Vaherva (Red.). Arkipäivän oppiminen. Aikuiskasvatuksen 39. vuosikirja. Helsinki: Kansanvalistusseura, 178-199.

19. Lindholm, A. (2005). Maailman parantajat.

Globalisaatiokrittiinen liike Suomessa. Helsinki: Gaudeamus.

Nordvall, H. I skärningspunkten mellan det globala och det lokala. Tolkningsprocesser och koalitionsbygge i organiseringen av lokala social forum. Linköping: Linköpings universitet.

20. Carr, W. 2006. Philosophy, methodology and action research. Journal of Philosophy of Education, 40 (4), 421-435.

21. Carr, W. \& Kemmis, S. (1986). Becoming critical. Education, knowledge and action research.

London and Philadelphia: Falmer Press.

22. Carr, W. (2000). Partisanship in educational research. Oxford: Review of Education, 26 (3/4), 437-449.

23. Kemmis, S. Smith, T.J. (red.) Enabling praxis. Challenges for education. Rotterdam: Sense Publishers.

24. Harva, U. (1955). Aikuiskasvatus. Johdanto aikuiskasvatuksen teoriaan ja työmuotoihin Suomessa. Helsinki: Otava.

Installationstal 8.5.2009, Åbo Akademi, Vasa 